\title{
Characteristics of Frequent Attenders At a Community Health Center
}

Judith A. Savageau, MPH, Martha McLoughlin, MD, Alina Ursan, MS, Yan Bai, MS, Matthew Collins, MD, and Suzanne B. Cashman, ScD

Background: As high utilizers of health care resources, frequent attenders to medical practices pose a significant issue for primary health care. Studies documenting content of visits and characteristics of frequent attenders have paid limited attention to community health center populations. This study profiles these high utilizers comparing them to non-frequent attenders.

Methods: Through medical record abstraction, retrospective and longitudinal patient data were obtained for a 30-month time period for 382 established patients.

Results: Older patients 45 to 64 years $(\mathrm{OR}=1.85$; 95\% CI: 0.92, 3.70) and Medicaid recipients $(\mathrm{OR}=3.22 ; 95 \%$ CI: $1.54,6.72)$ were more likely to be frequent attenders. Patients residing furthest away from the $\mathrm{CHC}$ were also the most frequent of attenders $(\mathrm{OR}=3.68 ; 95 \% \mathrm{CI}: 1.22,11.13)$, as were those with a diagnosis of diabetes $(\mathrm{OR}=5.03 ; 95 \%$ CI: $2.17,11.70)$ or depression $(\mathrm{OR}=1.85 ; 95 \%$ CI: 0.96, 3.56). Patients who used the Emergency Department more $(\mathrm{OR}=1.54$; 95\% CI: 1.23,1.91) had the highest number of visits, although those patients who missed more appointments as a proportion of the number of scheduled appointments were less likely to be frequent attenders $(\mathrm{OR}=0.49$; $95 \% \mathrm{CI}$ : 0.36, 0.66).

Conclusions: Through developing interventions such as customized social report cards and applying elements of the Chronic Care Model, these results can help administrators and policy makers ensure that frequent attenders are cared for adequately and that safety net providers' resources are appropriate to the tasks demanded of them. (J Am Board Fam Med 2006;19:265-75.)

Studies have documented variation in content as well as in frequency of visits in family medicine encounters. ${ }^{1-7}$ One of the aims of this body of research has been to help practices understand how to care for frequent attenders who do not seem to need frequent medical visits. ${ }^{1}$ As high utilizers of health care resources, frequent attenders to medical practices-patients who make 5 to 12 or more visits per year-pose a significant issue for primary health care. Researchers have concluded that pa-

Submitted 16 August 2005; revised 31 October 2005; 8 November 2005.

From the Office of Community Programs (SBC), Department of Family Medicine and Community Health (JAS, MM, SBC), University of Massachusetts Medical School, Worcester, MA; Department of Statistics, Worcester Polytechnic Institute, Worcester, MA (AU, YB); and Family Health Center of Worcester, Worcester, MA (MC).

Funding: This project was funded through an Interagency Service Agreement between the Massachusetts Division of Medical Assistance and the University of Massachusetts Medical School.

Corresponding author: Judith A. Savageau, MPH, Department of Family Medicine and Community Health, University of Massachusetts Medical School, 55 Lake Avenue North, Worcester, MA 01655 (E-mail: judith.savageau@umassmed.edu). tients who are in the top few percentiles of total number of annual visits contribute anywhere from $15 \%$ to $30 \%$ of all visits. ${ }^{2,5,6,8,9}$ This places a drain on limited health care resources, increases provider workload, and contributes to physician frustration.

Research into the characteristics of frequent attenders has described this patient population as less likely to have social supports and more likely to have a lower perception of health status, a greater number of physical and psychological diagnoses, and to somatize more than patients categorized as not being frequent attenders. ${ }^{4,7,10-14}$ They are also more likely to be unemployed ${ }^{3,15}$ and/or on disability, ${ }^{16}$ as well as to be of lower socioeconomic status. ${ }^{1,8,11,15,17,18}$ An exception to this profile occurs when evaluating patient visits for preventive medical care-in that case, patients in higher social classes have been found to be more likely to seek medical care. ${ }^{14}$ Studies performed to determine the types of visits frequent attenders are making to their physicians have classified them into such categories as: entirely physical, clear psychological illness, crisis patients, chronically somatizing patients, and patients with multiple problems. ${ }^{19} \mathrm{With}$ 
various other categorizations used to describe these visits, ${ }^{18}$ classification has been suggested as a way to improve the management of patients' problems while boosting patient and physician satisfaction. ${ }^{1}$ Possibly even more importantly, with a deeper understanding of the reasons prompting frequent attenders' visits, sites may be able to direct patients to other, more appropriate (and possibly nonmedical) sites for problem resolution. Ideally, this would obviate the need for frequent visits without jeopardizing patients' health.

Sociodemographic characteristics of frequent attenders, as described in the literature, include female gender, ${ }^{3,20-23}$ increased age (especially among those 65 years of age and older), ${ }^{17,20,21}$ and marital status (specifically divorced and widowed persons). ${ }^{17}$ All these characteristics may be related to decreased social support networks, as well as higher stress levels, thus translating into higher use of health care services. ${ }^{24}$

Whereas the body of research examining frequent attenders for health care services provides interesting and useful insights into the characteristics of these patients, few if any studies have been done in the segment of the nation's safety net system represented by federally recognized community health centers. Our health care systemparticularly community health centers and other components that are considered part of the safety net-is struggling to meet a growing demand for its services. ${ }^{25}$ The mission of federally qualified community health centers, ie, to provide "affordable and comprehensive primary health care to medically underserved persons, ${ }^{25}$ has been a hallmark characteristic since their founding 40 years ago. To be considered a federally qualified health center, a community health center must: be located in or serve a medically underserved community; have nonprofit, public, or tax exempt status; offer comprehensive primary care and support services; provide services regardless of patient ability to pay and offer a sliding fee scale; and be governed by a board, the majority of whose members are health center patients. ${ }^{26}$ Understanding the characteristics of frequent attenders to community health centers-including the reasons for their visits-can provide information and understanding crucial to modifying our system of care so that it can meet these patients' needs while ensuring an appropriate locus of service. This study, an initial exploration into a previously unexamined issue, reports on the fea- tures and characteristics of frequent attenders to one community health center in Central Massachusetts. Founded more than 30 years ago, much like its urban counterparts throughout the country, this federally qualified community health center serves a diverse, low-income, marginalized city-dwelling population.

\section{Methods}

This cross-sectional study was part of a larger intervention demonstration project aimed at examining interdisciplinary, collaborative care. Described in greater detail elsewhere, ${ }^{27,28}$ the study was conducted at an urban family practice community health center (CHC) in Massachusetts that also serves as a Family Medicine residency training site. Incorporated as a federally qualified CHC in 1972, this site's mission is to improve the health and well being of traditionally underserved and culturally diverse people in the area. Patient care is provided by faculty family practice physicians, nurse practitioners, physician assistants, and residents, along with registered nurses and medical assistants. At the time this study began, ie, 1999, the health center saw 17,555 patients during the year; slightly more than half $(58 \%)$ were female; $43 \%$ were Hispanic, 12\% African American, 7\% Asian, and 33\% White; $78 \%$ of the patients had publicly funded or no health insurance.

Medical records of 465 adult patients scheduled to receive care at the health center during one study week in February 1999 were audited. Both retrospective and longitudinal patient data were obtained for a 30-month time period, from August 1998 to February 2001. Data were abstracted from the problem list, the progress notes, and a demographic profile included in patients' medical records. Sociodemographic factors, as well as chronic problems, numbers of scheduled, kept, and missed visits, referrals, preventive measures, emergency department use, and hospitalizations were collected from the patients' charts. Nurse abstractor interrater reliability analyses produced high intraclass correlations. Interrater reliability analyses conducted for ordinal and continuous variables produced intraclass correlations between 0.86 and 0.99. Kappa statistics for categorical items ranged from 0.88 to 0.94 .

For this segment of the overall research project, the outcome variable of interest was the classifica- 
tion of patients as "frequent" versus "non-frequent attenders." Health center visits, including routine health care maintenance, acute care, and follow-up visits, for all 465 patients, were counted. Based on a review of the literature and the many descriptions used by other investigators, ${ }^{4,5,6,29}$ the cutoff chosen for defining frequent attendance was the 75 th percentile of all outpatient primary care site patient visits during the 30 -month study period, ie, having $15+\mathrm{CHC}$ visits during the study time frame. Subsequently excluded from the original study cohort of 465 adults were patients who had only one, first-time visit to the health center.

To explore the potential relationship between a patient's frequent use of the health center and health status, a brief health profile was developed for each patient. The profile consisted of an individual's psychological and/or chronic physical conditions recorded in the medical record during the 30-month study period. Chronic physical conditions included conditions sufficiently common that they were present in at least $10 \%$ of this patient cohort. Seven conditions (hypertension, diabetes, asthma, obesity, arthritis, chronic pain, and gastroesophageal reflux disease) met this criterion. Psychological conditions included a range of diagnoses that encompassed mood and anxiety disorders, thought, somatoform (manifestation of generalized physical symptoms that result from psychological conflict), and personality disorders. The resulting health status variable was included in the analyses as a continuous, ie, the total number of diagnoses/ conditions, as well as a dichotomous, ie, present/ absent, variable. The relationships between frequent attendance and both psychological and physical chronic conditions were examined individually for both variable types.

Analyses were organized around comparisons of those patients categorized as being frequent versus non-frequent attenders. Simple frequency distributions were used to describe the patient cohort and to examine characteristics of patients classified as frequent attenders. Using a conservative level of statistical significance $(P<.20)$, bivariate analyses were performed using $t$ tests or $\chi^{2}$, as appropriate, to select the independent variables for inclusion in the final logistic regression multivariate analyses. Age and gender were controlled for in all multivariate modeling. All analyses were conducted using SPSS version 12 (SPSS, Inc.); a value of $P=.05$ defined statistical significance in the multivariate analyses. This study was approved by both the community health center's and the university's institutional review boards for the conduct of research with human subjects.

\section{Results}

During the 30-month study period, 382 (81.9\%) of 465 patient records abstracted represented the pool of established patients seen at the $\mathrm{CHC}$ (ie, this was not their first and only visit to the health center). Of those, data on number of visits were complete for 381 patients, representing the study sample. All but 3 established patients had at least one visit during the study period; the number of visits ranged from 0 to 59 (mean $=10.30 ; \mathrm{SD}=8.12)$. Seventy-nine patients $(20.7 \%)$ were categorized as being frequent attenders, ie, having $15+$ visits during the 30 months.

With exceptions related to patients' insurance coverage and sex, sociodemographic characteristics of the sample population reflect those of the larger clinic population at the time the study was conducted (Table 1). Covering $57.4 \%$ of patients in the sample, Medicaid was the primary source of insurance for the 382 patients in the study sample; another $17.2 \%$ of patients were eligible for free care or had no source of third party payment. Patients' mean age was 42 years (range, 18 to 87 years; SD = 15). Approximately one-third (35.6\%) of the charts reported the patient's primary race as white; $46.9 \%$ did not have race noted. Among those with race noted, two-thirds $(67.0 \%)$ were white. In $39.5 \%$ of the medical records, patient ethnicity was listed as Hispanic; in another $40.3 \%$, patient ethnicity had not been recorded. Among those records with ethnicity reported, $66.2 \%$ of the sample was described as Hispanic.

Table 2 displays the relationship between frequent and non-frequent attenders' sociodemographic characteristics, health status indicators, and health care utilization.

\section{Sociodemographic Factors}

Patient age, ZIP code of residence, and insurance status were the only significant sociodemographic characteristics associated with frequent health center attendance. Patients aged 45 to 64 and those 65 years and older were more likely to have had frequent visits $\left(\chi^{2}=18.52 ; P<.001\right)$. The mean age of those patients seen frequently was also signifi- 
Table 1. Frequency and Percentage of Distributions of Study Sample, Study Pool, and Health Center Population Overall

\begin{tabular}{|c|c|c|c|}
\hline & $\begin{array}{l}\text { Study Pool } \\
(\mathrm{N}=465)^{*} \\
\mathrm{n}(\%)\end{array}$ & $\begin{array}{c}\text { Study Sample } \\
(\mathrm{N}=382) \dagger \\
\mathrm{n}(\%)\end{array}$ & $\begin{array}{c}\text { CHC Patient Population Overall } \\
\text { (Data Obtained from UDS Reports) } \ddagger \\
\%\end{array}$ \\
\hline \multicolumn{4}{|l|}{ Gender } \\
\hline Male & $136(29.5)$ & $108(28.3)$ & 42 \\
\hline Female & $329(70.5)$ & $273(71.7)$ & 58 \\
\hline \multicolumn{4}{|l|}{ Insurance } \\
\hline Medicaid & $258(56.1)$ & $217(57.4)$ & 47 \\
\hline Medicare & $68(14.8)$ & $62(16.4)$ & 9 \\
\hline Private & $43(9.3)$ & $34(9.0)$ & 10 \\
\hline None/self-pay & $91(19.8)$ & $65(17.2)$ & 31 \\
\hline \multicolumn{4}{|l|}{ Race $\$$} \\
\hline American Indian & $4(0.9)$ & $3(0.8)$ & 0 \\
\hline Asian & $28(6.0)$ & $27(7.1)$ & 7 \\
\hline Black & $45(9.7)$ & $37(9.7)$ & 12 \\
\hline White & $159(34.2)$ & $136(35.6)$ & 33 \\
\hline \multicolumn{4}{|l|}{ Ethnicity\| } \\
\hline Hispanic & $188(40.4)$ & $151(39.5)$ & 43 \\
\hline
\end{tabular}

* Includes those patients for whom chart abstractions were completed during the 30-month study period (variable levels may not total 465 because of sporadic missing data).

† Excludes those patients for whom there was only one visit that represented the patient's first visit to the health center (variable levels may not total 382 because of sporadic missing data).

‡ Federal Government Uniform Data System Report for the reporting period January 1998 to December 1998; reflects the population at the time the study commenced.

$\$$ Data on race were missing from a significant number of the medical records abstracted $(49.2 \%$ of the data on race were missing from the medical records of the study pool and from $46.9 \%$ of the study sample's charts). Data in the table represent percentages from those charts where race was abstracted.

|| Data on ethnicity was missing from a significant number of the medical records abstracted $(40.2 \%$ of the data on ethnicity was missing from the medical records of the sample pool and from $40.3 \%$ of the study sample's charts).

cantly higher (mean $=48.65, \mathrm{SD}=14.15)$ than that of patients not seen frequently (mean $=40.46$, $\mathrm{SD}=14.89 ; t=4.40 ; P<.001)$. There was a trend for those patients living outside of the city limits to visit the $\mathrm{CHC}$ more frequently compared with those residing in the $\mathrm{CHC}$ catchment area or those outside of that catchment area but within the city limits $\left(\chi^{2}=4.82 ; P=.09\right)$. Frequent visits to the health center were also significantly related to insurance coverage by Medicaid or Medicare compared with private insurance or uninsured and selfpay patients $\left(\chi^{2}=16.75 ; P=.001\right)$. Not surprisingly, patients with no insurance or who were part of the free care pool were far less likely to visit the health center. Frequent attendance was not significantly associated with gender, marital status, or provider type. Because of the significant amount of missing medical record data for primary language, race, and ethnicity, we did not test for significant relationships between these variables and frequent attendance.

\section{Health Indicators}

Two-thirds $(67.3 \%)$ of all patients in the study had at least one of the included chronic physical problems (as defined above in the patient's health profile) and $40.6 \%$ had at least one chronic psychological condition. Reflecting the high burden of chronic illness seen throughout the health center's patient population, among those categorized as frequent attenders, 9 out of 10 patients $(89.9 \%)$ had at least one chronic medical condition and just over half $(57.0 \%)$ had at least one chronic psychological condition listed in their medical records. When analyzed individually, conditions that were associated with higher visit frequency included hypertension, diabetes, and depression $\left(\chi^{2}=3.15 ; P=.076\right.$, $\chi^{2}=23.67 ; P<.001$, and $\chi^{2}=11.73 ; P=.001$, respectively). Smoking status and obesity were not related to more frequent visits. Further examination of the number of chronic problems revealed that there was a highly significant relationship between the number of physical chronic problems 
Table 2. Frequency and Percentage of Distributions of Demographic, Health Status, and Utilization Characteristics Comparing Frequent and Non-frequent Attenders $(\mathrm{N}=381) *$

\begin{tabular}{|c|c|c|c|c|}
\hline & $\begin{array}{l}\text { Frequent Attenders } \\
\qquad(\mathrm{N}=79)\end{array}$ & $\begin{array}{l}\text { Non-frequent Attenders } \\
\qquad(\mathrm{N}=302)\end{array}$ & Statistic $†$ & $P$ Value \\
\hline \multicolumn{5}{|l|}{ Sociodemographic factors } \\
\hline \multicolumn{5}{|l|}{ Age group } \\
\hline 18 to 44 years & $30(37.9 \%)$ & $195(64.6 \%)$ & \multirow[t]{3}{*}{$\chi^{2}=18.521$} & \multirow[t]{3}{*}{$<.001$} \\
\hline 45 to 64 years & $39(49.4 \%)$ & $88(29.1 \%)$ & & \\
\hline $65+$ years & $10(12.7 \%)$ & $19(6.3 \%)$ & & \\
\hline Mean age (SD) & $48.65(14.15)$ & $40.46(14.89)$ & $t$ test $=4.395$ & $<.001$ \\
\hline \multicolumn{5}{|l|}{ Gender } \\
\hline Male & $18(22.8 \%)$ & $90(29.8 \%)$ & \multirow[t]{2}{*}{$\chi^{2}=1.518$} & \multirow[t]{2}{*}{ NS } \\
\hline Female & $61(77.2 \%)$ & $212(70.2 \%)$ & & \\
\hline \multicolumn{5}{|l|}{ ZIP code of residence } \\
\hline Within the $\mathrm{CHC}$ catchment area & $20(25.6 \%)$ & $85(28.2 \%)$ & \multirow[t]{3}{*}{$\chi^{2}=4.823$} & \multirow[t]{3}{*}{.090} \\
\hline $\begin{array}{l}\text { Within the city, but outside the } \\
\text { catchment area }\end{array}$ & $48(61.5 \%)$ & $199(66.1 \%)$ & & \\
\hline Outside of the city limits & $10(12.8 \%)$ & $17(5.6 \%)$ & & \\
\hline \multicolumn{5}{|l|}{ Marital Status } \\
\hline Not currently married & $45(73.8 \%)$ & $182(69.7 \%)$ & \multirow[t]{2}{*}{$\chi^{2}=0.388$} & \multirow[t]{2}{*}{ NS } \\
\hline Married & $16(26.2 \%)$ & $79(30.3 \%)$ & & \\
\hline \multicolumn{5}{|l|}{ Insurance Status } \\
\hline Medicaid & $53(67.1 \%)$ & $163(54.7 \%)$ & \multirow[t]{4}{*}{$\chi^{2}=16.754$} & \multirow[t]{4}{*}{.001} \\
\hline Medicare & $19(24.1 \%)$ & $43(14.4 \%)$ & & \\
\hline Private & $2(2.5 \%)$ & $32(10.7 \%)$ & & \\
\hline None/self-pay/Free Care & $5(6.3 \%)$ & $60(20.1 \%)$ & & \\
\hline \multicolumn{5}{|l|}{ Provider type } \\
\hline MD/attending & $39(49.4 \%)$ & $143(47.4 \%)$ & \multirow[t]{3}{*}{$\chi^{2}=0.165$} & \multirow[t]{3}{*}{ NS } \\
\hline $\mathrm{NP}$ or $\mathrm{PA}$ & $22(27.8 \%)$ & $91(30.1 \%)$ & & \\
\hline Resident & $18(22.8 \%)$ & $68(22.5 \%)$ & & \\
\hline \multicolumn{5}{|l|}{ Health indicators } \\
\hline \multicolumn{5}{|l|}{ Smoking status } \\
\hline Not currently smoking & $45(60.0 \%)$ & $167(60.3 \%)$ & \multirow[t]{2}{*}{$\chi^{2}=0.002$} & NS \\
\hline Currently smoking & $30(40.0 \%)$ & $110(39.7 \%)$ & & \\
\hline Hypertension & & & & \\
\hline No & $53(67.1 \%)$ & $232(76.8 \%)$ & $\chi^{2}=3.147$ & .076 \\
\hline Yes & $26(32.9 \%)$ & $70(23.2 \%)$ & & \\
\hline Diabetes & & & & \\
\hline No & $55(69.6 \%)$ & $274(90.7 \%)$ & $\chi^{2}=23.674$ & $<.001$ \\
\hline Yes & $24(30.4 \%)$ & $28(9.3 \%)$ & & \\
\hline Obesity $\ddagger$ & & & & \\
\hline No & $33(41.8 \%)$ & $155(51.3 \%)$ & $\chi^{2}=2.286$ & NS \\
\hline Yes & $46(58.2 \%)$ & $147(48.7 \%)$ & & \\
\hline Depression & & & & \\
\hline No & $42(53.2 \%)$ & $221(73.2 \%)$ & $\chi^{2}=11.733$ & .001 \\
\hline Yes & $37(46.8 \%)$ & $81(26.8 \%)$ & & \\
\hline Number of chronic physical conditions & & & & \\
\hline None & $8(10.1 \%)$ & $116(38.4 \%)$ & $\chi^{2}=22.818$ & $<.001$ \\
\hline One or more & $71(89.9 \%)$ & $186(61.8 \%)$ & & \\
\hline Mean number of chronic problems (SD) & $2.27(1.28)$ & $1.10(1.16)$ & $t$ test $=7.803$ & $<.001$ \\
\hline Number of chronic psychological conditions & & & & \\
\hline None & $34(43.0 \%)$ & $193(63.9 \%)$ & $\chi^{2}=11.325$ & .001 \\
\hline One or more & $45(57.0 \%)$ & $109(36.1 \%)$ & & \\
\hline Mean number of chronic problems (SD) & $0.75(0.78)$ & $0.50(0.75)$ & $t$ test $=2.619$ & .009 \\
\hline
\end{tabular}




\begin{tabular}{|c|c|c|c|c|}
\hline & $\begin{array}{l}\text { Frequent Attenders } \\
\qquad(\mathrm{N}=79)\end{array}$ & $\begin{array}{l}\text { Non-frequent Attenders } \\
\qquad(\mathrm{N}=302)\end{array}$ & Statistic $†$ & $P$ Value \\
\hline \multicolumn{5}{|l|}{ Utilization Factors } \\
\hline \multicolumn{5}{|l|}{ Number of ER visits } \\
\hline None/One & $51(66.2 \%)$ & $268(90.5 \%)$ & $\chi^{2}=29.158$ & $<.001$ \\
\hline $2+$ & $26(33.8 \%)$ & $28(9.5 \%)$ & & \\
\hline Mean number of ER visits (SD) & $1.35(1.72)$ & $0.50(1.32)$ & $t$ test $=4.019$ & $<.001$ \\
\hline \multicolumn{5}{|c|}{$\begin{array}{l}\text { Proportion of missed appointments based } \\
\text { on number of scheduled appointments }\end{array}$} \\
\hline$<50 \%$ & $77(100.0 \%)$ & $241(81.7 \%)$ & $\chi^{2}=16.488$ & $<.001$ \\
\hline$\geq 50 \%$ & $0(0.0 \%)$ & $54(18.3 \%)$ & & \\
\hline Mean proportion (SD) & $0.1294(0.1012)$ & $0.2730(0.2141)$ & $t$ test $=8.459$ & $<.001$ \\
\hline
\end{tabular}

NS, not significant.

* Some numbers may not add up to $\mathrm{N}=381$ because of sporadic missing data.

$\dagger \chi^{2}$ tests were used for categorical independent variables; $t$ tests were used for continuous independent variables; all $t$ tests were recomputed using Mann-Whitney $U$ nonparametric tests because of skewness in the numbers of ED visits, missed appointments, and chronic problems (no differences in interpretation of the relationship between these variables and the outcome were found).

¥ Patients were categorized as being obese or not based on the notation of this diagnosis on the chronic problem list as well as through the calculation of their body mass index using height and weight data indicated in their medical record.

$\left(\chi^{2}=22.82 ; P<.001\right)$ as well as the number of chronic psychological problems $\left(\chi^{2}=11.33 ; P=\right.$ $.001)$ and frequent visits to the health center. Among frequent versus non-frequent patient attendees, the mean number of chronic physical problems was double (mean $=2.27, \mathrm{SD}=1.28$ and mean $=1.10, \mathrm{SD}=1.16$, respectively; $t=7.80$, $P<$.001). Similarly, the mean number of chronic psychological problems was $50 \%$ higher among frequent health center visitors (mean $=0.75, \mathrm{SD}=$ 0.78 ) compared with those patients seen fewer than 15 times in the 30-month study period (mean = $0.50, \mathrm{SD}=0.75 ; t=2.62 ; P=.009)($ Table 2$)$.

\section{Utilization Factors}

Frequent use of the health center (as defined by kept appointments) was also related to frequent Emergency Department (ED) utilization as well the proportion of missed visits as a function of the number of scheduled appointments. The percentage of patients with 2 or more ED visits over the 30-month time frame (allowing a "grace" of one during the study period) was significantly higher for frequent attenders (33.8\%) compared with patients seen less frequently $\left(9.5 \% ; \chi^{2}=29.16 ; P<\right.$ .001). The number of ED visits for all patients ranged from 0 to 11 ; however, the mean number of ED visits for frequent attenders was more than double that of their non-frequent counterparts $($ mean $=1.35, \mathrm{SD}=1.72$ vs. mean $=0.50, \mathrm{SD}=$
1.32; $t=4.02 ; P<.001)$. Rather than assess the actual number of missed appointments and its relationship to frequency of visits, we calculated the proportion of missed visits relative to the number of scheduled visits and assessed the relationship between this proportion and frequent attendance, both as a continuous and a categorical variable using a $50 \%$ cutoff. In assessing the percentage of patients who missed $50 \%$ or more of their scheduled visits, none of those in the frequent attender group had $50 \%$ or more of their scheduled appointments missed compared with $18.3 \%$ of the non-frequent attenders $\left(\chi^{2}=16.49 ; P<.001\right)$. As Table 2 shows, the mean proportion of failed appointments (in relation to the number of scheduled visits; ranging from 0 to $100 \%$ for the group as a whole) was significantly lower for frequent attenders (mean $=0.1294, \mathrm{SD}=0.1012)$ compared with patients with fewer visits (mean $=0.2730, \mathrm{SD}=$ $0.2141 ; t=8.46 ; P<.001)$.

\section{Multivariate Analyses}

To identify factors that contributed most to frequent attendance, a stepwise multivariate logistic regression was employed, controlling for age and gender (Table 3). The variable "frequent visits," ie, 15 or more visits in a 30 -month period, was associated with residence outside of the city limits, Medicaid insurance coverage, the independent diagnoses of diabetes and depression, increased ED 


\begin{tabular}{|c|c|c|}
\hline Independent Factors & $\begin{array}{l}\text { Number (and Percentage of } \\
\text { Distribution) of Frequent Attenders } \\
(\mathrm{N}=79)\end{array}$ & $\begin{array}{c}\text { Frequent Attenders OR } \\
\text { (95\% CI) Model \% } \\
\text { Predicted Correctly }=84.4\end{array}$ \\
\hline \multicolumn{3}{|l|}{ Age } \\
\hline 18 to 44 years & $30(37.9 \%)$ & 1.0 \\
\hline 45 to 64 years & $39(49.4 \%)$ & $1.849(0.924,3.701)$ \\
\hline $65+$ years & $10(12.7 \%)$ & $2.199(0.667,7.248)$ \\
\hline \multicolumn{3}{|l|}{ Gender } \\
\hline Male & $18(22.8 \%)$ & 1.0 \\
\hline Female & $61(77.2 \%)$ & $1.271(0.618,2.616)$ \\
\hline \multicolumn{3}{|l|}{ ZIP code of residence } \\
\hline Inside $\mathrm{CHC}$ catchment area & $21(25.7 \%)$ & 1.0 \\
\hline Inside city/outside $\mathrm{CHC}$ catchment area & $48(61.5 \%)$ & $0.730(0.355,1.503)$ \\
\hline Outside city limits & $10(12.8 \%)$ & $3.676(1.215,11.125)$ \\
\hline \multicolumn{3}{|l|}{ Medicaid insurance coverage } \\
\hline No & $26(32.9 \%)$ & 1.0 \\
\hline Yes & $53(67.1 \%)$ & $3.221(1.543,6.721)$ \\
\hline \multicolumn{3}{|l|}{ Diabetes } \\
\hline No & $55(69.6 \%)$ & 1.0 \\
\hline Yes & $24(30.4 \%)$ & $5.034(2.165,11.704)$ \\
\hline \multicolumn{3}{|l|}{ Depression } \\
\hline No & $42(53.2 \%)$ & 1.0 \\
\hline Yes & $37(46.8 \%)$ & $1.847(0.960,3.557)$ \\
\hline $\begin{array}{l}\text { Number of ER visits } \\
\quad \text { (continuous variable) }\end{array}$ & $\begin{array}{l}\text { Mean: } 1.35 \\
(\mathrm{SD}: 1.72)\end{array}$ & $1.535(1.232,1.914)$ \\
\hline $\begin{array}{l}\text { Number of missed appointments (as a proportion } \\
\text { of scheduled appointments) } \\
\text { (continuous variable) }\end{array}$ & $\begin{array}{l}\text { Mean: } 0.1294 \\
\text { (SD: 0.1012) }\end{array}$ & $0.487(0.362,0.656)$ \\
\hline Intercept & & 0.177 \\
\hline
\end{tabular}

utilization, and decreased numbers of missed appointments (as a proportion of scheduled visits). Depression and patient age (45 to 64 years) were of borderline significance but still worthy of note given their clinical relevance. This model predicted $84.4 \%$ of all cases correctly $(96.2 \%$ of those nonfrequent attenders and $37.5 \%$ of the frequent attenders; the Nagelkerke estimated $R^{2}$ was 0.39 ). The model goodness-of-fit was not significant (Hosmer-Lemeshow goodness-of-fit $\chi^{2}=10.89$, $P=.208)$, indicating an adequate model fit to the data.

\section{Discussion}

This study reaffirms conclusions of previous studies that have identified and analyzed characteristics of patients known as "frequent attenders", 3,4,6,7,17; more importantly, however, by conducting the research in a setting that has not been examined previously, it expands the current knowledge base. By extending the context of the work to include one of the nation's most valued safety net providers, ie, the federally qualified community health center, the research reported on in this study can help policy makers, administrators, and clinicians as they attempt to meet the needs of a predominantly lowincome patient population. This is critical to ensuring that the limited resources of community health centers are not overwhelmed.

The fact that frequent attenders in the community health center where this study was conducted are more likely to be older and on some type of public insurance is consistent with what is known about frequent attenders in primary care settings in general. Our study did not find, however, that frequent attenders are more likely to be female. This may be a result of the study site's having been founded on and having maintained a strong family medicine philosophy that encourages all family members to visit the health center. It could also reflect the generally compromised health status of a predominantly low-income patient population 
whose health is poorer than that of the general population $^{30}$ and, thus, more likely overall to seek care, especially at a facility whose stated aim is to turn no one away.

Few studies of frequent attenders have included place of residence as a variable. The finding that patients who live further away from the health center made more visits than patients who live nearby was unexpected. This result may be driven by the patients at a further distance having difficulty obtaining care in facilities closer to them (because of limited ability to pay), having fewer nearby facilities, or a combination of these factors. Alternatively, it could reflect a greater need among patients who live further away for the type of social supports that federally funded community health centers provide.

It was interesting that when multivariate analysis was conducted, number of physical diagnoses failed to attain significance, but the diagnosis of diabetes was significant in and of itself. Previous studies have shown that frequent attenders are more likely to have musculoskeletal problems, ${ }^{8,10,20}$ digestive/gastrointestinal difficulties, ${ }^{8,31}$ and respiratory symptoms. ${ }^{6,31}$ If the diagnosis of diabetes is viewed as part of a metabolic syndrome that includes overweight, hypercholesterolemia, hypertension, and pre-diabetes, it may be capturing other chronic conditions that were not significant as independent factors but which contribute to the single diagnosis of diabetes attaining statistical significance. The diagnosis of diabetes may also be reflecting a positive association with age distribution; although frequent attenders were more likely to be older, this association failed to retain significance in the multivariate analysis.

Given the relatively poorer health status of frequent attenders, it is not surprising that members of this subgroup were also higher users of the ED. Studies of patient use of the ED have generally attempted to characterize patients who did versus those who did not need the high level of care available at an ED. We did not attempt to determine the level of appropriateness of the $\mathrm{ED}$ visit in this patient cohort; rather, it is instructive to learn that frequent users of the primary care providers' offices are also more likely to be among the frequent users of the ED. It seems that, as one researcher has suggested, patients connect with the health care system because they have reached the limits of symptom tolerance or anxiety tolerance.
"Reaching these limits may cause patients to make whatever type of medical contact seems most feasible to them at the time." ${ }^{32}$ This contact includes the ED, although the community health center where this study was conducted has an urgent care department and all patients are encouraged to use it if they have difficulty obtaining a same-day appointment.

The utilization picture of the frequent attender that develops from this study's data indicates that this subgroup makes and keeps more appointments than their nonfrequent attender counterparts. The positive association between age and likelihood of keeping an appointment may also explain the fact that in our model, although age is statistically significant at the bivariate level, it fails to attain significance in the multivariate analysis. Nevertheless, it is noteworthy that frequent attenders do not miss a higher proportion of their scheduled appointments. This supports the "hypothesis of more vulnerability" among frequent attenders as described by others ${ }^{6}$ and contributes to the understanding of frequent attenders as patients who place great reliance on this safety net component of our health care system.

Thirty years ago, in a study of frequent attenders at a general practice health center in the United Kingdom, a recommendation was made that once a patient was considered a frequent attender, "a social report could, when thought appropriate, be requested...."33 Not only does it seem that this recommendation is as timely today as it was more than a quarter century ago, but it could also be viewed as a precursor to the current Chronic Care Model. ${ }^{34}$ Given the profile of the frequent attender to a community health center that emerges from this study, ie, an individual who is older, on public assistance, has diabetes, visits the ED frequently as well as makes and keeps appointments, implementing the system changes for which the Chronic Care Model calls could help community health centers meet the needs of this subpopulation. Several elements of the model are particularly germane. These include: (1) identification and activation of community resources; (2) support for self-management; (3) delivery system design; and (4) interaction between an informed, activated patient with a prepared, proactive practice team. Identification and activation of community resources is essential to ensuring that patients are likely to get the right type of care in the right type of setting. The fact 
that frequent attenders tend to schedule and keep more appointments than others reflects a degree of need and vulnerability that a connection to community resources could help manage. Generally non-medical services, these community resources may be less expensive and more appropriate to meeting particular individuals' needs. As natural collaborators, community health centers should be well situated to ensure that, possibly with help from community health workers or other liaison staff, these connections result in effective referral mechanisms. In Massachusetts as in several other states, advocacy initiatives related to ensuring that outreach workers are included as paid members of the health care team have gained wide support. ${ }^{35,36}$

With self-management support, patients develop a better understanding of their own particular needs as well as a clearer grasp of how to meet them. Again, a role for medical assistants or community health workers appears, as these staff members may be well situated to initiate this type of management. It is interesting that recent reports related to developing the future of family medicine call for a more active role for medical assistants. ${ }^{37}$ This could include developing and implementing self-management plans.

Delivery system design calls for scheduled follow-up care; this element complements the Chronic Care model's component termed "Clinical Information System" and its specification of the importance of carrying out individual care planning. If these follow-up care visits were to include individual care plans that patients help draft, they might "own" more of their medical issues and work with providers to develop plans for problem resolution. Furthermore, with follow-up visits scheduled with the appropriate caregiver, given that frequent attenders are more likely to keep their appointments, this type of proactive oversight may reduce spontaneous visits to the ED.

Finally, productive interaction between an informed, activated patient with a prepared, proactive practice team means that the patient can be cared for by an interprofessional team whose members know and understand the range of the patient's issues that may render him or her particularly vulnerable and thus reliant on medical care. This can ensure a role for the medical assistant and community health worker that could include support groups and management of physical as well as mental health needs outside of the provider office context.

In striving to match provider supply with patient demand, clinical systems generally compute an expected size of a provider's (either physician or nurse practitioner) patient panel. This reflects a desired provider-to-patient ratio overall. To develop a match that results in an efficient, effective use of an expensive, scarce resource, ie, the physician or nurse practitioner, administrators often base the patient panel size on an estimated average number of annual visits per patient. The health center where this study was conducted reports an average of 3.7 patient visits per year and an inability to meet recommended average patient visit benchmarks. Average figures, of course, incorporate the fact that some patients make many visits in a year whereas others make few or none. Nevertheless, for systems that have a high proportion of frequently attending patients, many of whom present with an array of complicated physical and psychological problems, a mismatch between supply and demand often exists. Studies such as the one reported on in this article can support administrators and policy makers as they attempt to ensure that frequent attender patients are cared for adequately and that the resources of the safety net providers-including services of staff other than physicians-are appropriate to the tasks demanded of them.

The present study was limited in scope; conducted at one community health center, it is limited in generalizability. Nevertheless, given the consistency of findings with previous research and the similarity of the study population to patients seen at other urban community health centers, it is reasonable to hypothesize that these findings would be replicated in clinics serving other low-income, urban patient populations. In addition, the study relied on data abstracted from charts alone and thus contains the possibly that information bias has been introduced. However, when select medical record data on scheduled and kept visits were compared with the CHC's billing/scheduling system, intraclass correlations ranged from 0.64 to 0.75 -lending confidence in our use of the chart audit data for these analyses. Furthermore, studies of patient populations frequently include race, language, and ethnicity data. Relying on medical charts, which have poor and/or large quantities of missing information for this data, precluded our ability to include these potentially important sociodemo- 
graphic characteristics. It is also the case that changes in patients' health status can occur over time; the dataset used for this study was not able to incorporate these changes if they occurred. Finally, no attempt was made to interview patients or their providers to learn their respective views regarding why they made frequent visits to the health center. This seems to be an important avenue for continued research on this topic.

Patients' frequency of visits is a long-standing issue. Concern that a small portion of patients is accounting for a large share of a facility's visit volume, particularly in safety net facilities serving low-income populations, means that research conducted in these settings can contribute valuable information to ensuring that an adequate match exists between provider supply and patient demand. To approach an equilibrium in resource-limited facilities, the unique needs of patients who are frequent attenders may need to be met through means other than the physician or the nurse practitioner. Applying elements of the Chronic Care Model to frequent attenders could result in more effective, efficient use of community health centers' resources while improving individuals' health status.

We thank Celeste Lemay, RN, BSN, Lael Eaton, RN, Christina Cuneo-Lareau, RN, Joan Thorne, RN, and Maria Laverty, RN, for conducting the extensive chart abstractions, as well as the participating health center's administrative and clinical staff for their contributions to this project. We also gratefully acknowledge Pam Tero for editorial assistance and Kenneth Fletcher, $\mathrm{PhD}$, for statistical consultation.

\section{References}

1. Smucker D, Zink T, Susman J, Crabtree B. A framework for understanding visits by frequent attenders in family practice. J Fam Pract 2001;50:847-52.

2. Neal RD, Heywood PL, Morley S, Clayden AD, Dowell AC. Frequency of patients consulting in general practice and workload generated by frequent attenders: comparisons between practices. Br J Gen Pract 1998;48:895-8.

3. Vedsted P, Fink P, Olesen F. Psychological distress as a predictor of frequent attendance in family practice: a cohort study. Psychosomatics 2001;42:41622.

4. Vedsted P, Fink P, Sorensen HT, Olesen F. Physical, mental and social factors associated with frequent attendance in Danish general practices. Soc Sci Med 2004;59:813-23.

5. Botica M, Kovacic L, Kujundzic Tiljak M, et al. Frequent attenders in family practice in Croatia: retrospective study. Croat Med J 2004;45:620-4.
6. Bergh H, Marklund B. Characteristics of frequent attenders in different age and sex groups in primary health care. Scand J Prim Health Care 2003;21: 171-7.

7. Bellon J, Delgado A, Luna J, Lardelli P. Psychosocial and health belief variables associated with frequent attendance in primary care. Psychol Med 1999;29: 1347-57.

8. Jyvasjarvi S, Keinanen-Kinkaanniemi S, Vaisanen E, Larivaara P. Frequent attenders in a Finnish health centre: morbidity and reasons for encounter. Scand J Prim Health Care 1998;16:141-8.

9. McFarland BH, Freeborn DK, Mullooly JP, Pope CR. Utilization patterns among long term enrollees in a prepaid group practice health maintenance organization. Med Care 1985;23:1221-33.

10. Karlsson H, Joukamaa M, Lahti I, Lehtinen V, Kokkisaanen T. Frequent attender profiles: different clinical subgroups among frequent attender patients in primary care. J Psychosom Res 1997;42:157-66.

11. Neal RD, Heywood PL, Morley S. Frequent attenders consulting patterns with general practitioners. Br J Gen Pract 2002;50:972-6.

12. Vedsted P, Olesen F. Frequent attenders in out-ofhours general practice care: attendance prognosis. Fam Pract 1999;16:283-8.

13. Callahan CM, Hui SL, Nienaber NA, Musick BS, Tierney WM. Longitudinal study of depression and health services use among elderly primary care patients. J Am Geriatr Soc 1994;42:833-8.

14. Katon W, Von Korff M, Lin E, et al. Distressed high utilizers of medical care. DSM-III-R diagnoses and treatment needs. Gen Hosp Psychiatry 1990;12:35562.

15. Scaife B, Gill P, Heywood P, Neal R. Socio-economic characteristics of adult frequent attenders in general practice-secondary analysis of data. Fam Pract 2000;17:298-304.

16. Mechanic D, Cleary PD, Greenley JR. Distress syndromes, illness behavior, access to care and medical utilization in a defined population. Med Care 1982; 20:361-72.

17. Karlsson H, Lehtinen V, Joukamaa M. Frequent attenders of Finnish primary health care: sociodemographic characteristics and physical morbidity. Fam Pract 1994;11:424-30.

18. Westhead JN. Frequent attenders in general practice: medical, psychological and social characteristics. JR Coll Gen Pract 1985;35:337-40.

19. Freeborn DK, Pope CR, Mullooly JP. Consistently high users of medical care among the elderly. Med Care 1990;28:527-40.

20. Ahmad AW, Dag E, Kurt S. The influence of sociodemographic characteristics on health care utilization in a Swedish municipality. Ups J Med Sci 2004; 109:33-42.

21. Andersson SO, Lynoe N, Hallgren CG, Nilsson, M. Is frequent attendance a persistent characteristic of a 
patient? Repeat studies of attendance patterns at the family practitioner. Scand J Prim Health Care 2004; 22:91-4.

22. Hiller W, Fichter MM. High utilizers of medical care: a crucial subgroup among somatizing patients. J Psychosom Res 2004;56:437-43.

23. Jyvasjarvi S, Joukamaa M, Vaisanen E, Larivaara P, Kivela SL, Keinanen-Kiukaanniemi S. Alexithymia, hypochondriacal beliefs and psychological distress among frequent attenders in primary health care. Compr Psychiatry 1999;40:292-8.

24. Dowrick C, Bellon J, Gomez M. General practice frequent attendance in Liverpool and Granada: the impact of depressive symptoms. Br J Gen Pract 2000; 50:361-5.

25. Rosenbaum S, Shin P, Darnell J. Economic stress and the safety net: a health center update. Washington (DC): Kaiser Commission on Medicaid and the Uninsured. June 2004.

26. Taylor J. The fundamentals of community health centers. Washington (DC): The George Washington University; August 31, 2004.

27. Cashman SB, Reidy P, Cody K, Lemay CA. Developing and measuring progress toward collaborative, integrated, interdisciplinary health care teams. J Interprof Care 2004;18:183-96.

28. Cashman SB, Savageau JA, Lemay CA, Ferguson W. Patient health status and appointment keeping in an urban community health center. J Health Care Poor Underserved 2004;15:474-88.

29. Gill D, Sharpe M. Frequent consulters in general practices: a systematic review of studies of preva- lence, association and outcome. J Psychosom Res 1999 Aug;47:115-30.

30. Cashman SB, Savageau JA, McMullen M, Kinney R, Lemay CA, Anthes F. Health status of a low-income vulnerable population in a community health center. J Ambul Care Manage 2005;28:60-72.

31. Robinson JO, Granfield AJ. The frequent consulter in primary medical care. J Psychosom Res 1986;30: 589-600.

32. Daugird AJ, Spencer DC. Characteristics of patients who highly utilize telephone medical care in private practice. J Fam Pract 1989;29:59-64.

33. McArdle C, Alexander WD, Boyle CM. Frequent attenders at a health center. Practitioner 1974;213: 696-702.

34. Wagner EH. Chronic disease management: what will it take to improve care for chronic illness? Effect Clin Pract 1998;1:2-4.

35. Massachusetts Community Health Worker, Legislation House 2751: An act providing for the investigation and study by the Department of Public Health relative to Community Health Workers. Filed, 12/04.

36. National Community Health Worker Workforce Development Study. University of Texas Health Science Center San Antonio, Regional Center for Workforce Development at the Center for Health Economics and Policy, 2003.

37. Society of Teachers of Family Medicine. Developing future of family medicine new model practices in residencies: learning from experience. Overview of the FFM and the new model. Society of Teachers of Family Medicine Preconference Workshop, 2005 April 30, New Orleans, LA. 